\title{
Microestrutura e condutividade elétrica do eletrólito sólido de céria-20\% mol gadolínia com adições de $\mathrm{SrO}, \mathrm{TiO}_{2}$ e $\mathrm{SrTiO}_{3}$
}

\section{(Microstructure and electrical conductivity of 20 mol\% gadolinia-doped ceria solid electrolyte with $\mathrm{SrO}, \mathrm{TiO}_{2}$ and $\mathrm{SrTiO}_{3}$ additions)}

\author{
M. C. F. Dias, E. N. S. Muccillo \\ Centro de Ciência e Tecnologia de Materiais, Instituto de Pesquisas Energéticas e Nucleares - IPEN, \\ R. do Matão, Travessa R, 400, Cidade Universitária, S. Paulo, SP 05508-000
}

\begin{abstract}
Resumo
Os efeitos da adição de $\mathrm{SrO}, \mathrm{TiO}_{2}$ e $\mathrm{SrTiO}_{3}$ na sinterização, na microestrutura e na condutividade elétrica do eletrólito sólido cériagadolínia foram sistematicamente investigados. Foram preparadas pelo método convencional de mistura dos reagentes de partida seguida de reação em estado sólido composições contendo 1,2,5 e 5\% mol dos aditivos. Diversas técnicas de caracterização foram utilizadas. Os resultados mostraram que os aditivos exercem influência em todas as propriedades estudadas, mas de forma diferente dependendo do tipo e do teor. De forma geral, o SrO tornou desprezível o bloqueio aos portadores de carga nos contornos de grão, mas prejudicou a densificação. $\mathrm{O} \mathrm{TiO}_{2}$ promoveu aumento substancial na densificação da céria-gadolínia, mas também no bloqueio exercido pelos contornos de grão, além de ser responsável pela exsolução do gadolínio e pela formação da fase pirocloro $\mathrm{Gd}_{2} \mathrm{Ti}_{2} \mathrm{O}_{7}$, quando adicionado em teores acima do limite de solubilidade. $\mathrm{O} \mathrm{SrTiO}_{3}$ não produziu alterações significativas na densificação, e resultou em aumento da condutividade intergranular pela diminuição da energia de ativação para o processo de condução.

Palavras-chave: eletrólito sólido, céria, densificação, microestrutura, condutividade elétrica.
\end{abstract}

\begin{abstract}
The effects of $\mathrm{SrO}, \mathrm{TiO}_{2}$ and $\mathrm{SrTiO}_{3}$ additions to gadolinia-doped ceria solid electrolyte were systematically investigated. Ceria-20 mol\% gadolinia containing 1, 2.5 and 5 mol\% of the secondary additives were prepared by mixing of the starting powders followed by solid state reaction at high temperature. Several characterization techniques were used. The results show that the final properties depend on the type and content of the additives. The blocking of charge carriers at the grain boundaries became negligible, but increase of porosity resulted in decrease of the relative density with SrO additions. Densification has been improved with minor amounts of $\mathrm{TiO}_{2}$, although this additive promoted the exsolution of the dopant from the matrix and consequent formation of the pyrochlore phase $\mathrm{Gd}_{2} \mathrm{Ti}_{2} \mathrm{O}_{7}$ for contents higher than the solubility limit. Additions of $\mathrm{SrTiO}_{3}$ did not influence the densification. However, increasing contents of this additive resulted in increase of the intergranular conductivity along with decreasing the activation energy for ion conduction.
\end{abstract}

Keywords: solid electrolyte, ceria, densification, microstructure, electrical conductivity.

\section{INTRODUÇÃO}

Cerâmicas policristalina à base de céria têm atraído a atenção de pesquisadores tanto do ponto de vista científico quanto tecnológico nas últimas décadas. Sua ampla gama de aplicações foi aumentada com o advento das nanoestruturas, que podem possibilitar a otimização e/ou desenvolvimento de novas propriedades. Algumas das já conhecidas e das potenciais aplicações das cerâmicas à base de céria são como catalisador em diversas reações químicas [1] meios de polimento mecânico na microeletrônica [2], sensor de gases [3], eletrólito e eletrodo sólidos para células a combustível de óxido sólido [4], material luminescente [5], e filtro e bloqueador de radiação ultravioleta $[6,7]$.

A introdução de aditivos na céria tem como função primordial modificar suas propriedades. Assim, por exemplo, a adição de terras raras trivalentes resulta em aumento substancial na sua condutividade iônica. Dentre as terras raras trivalentes, aquelas que possibilitam maior aumento na condutividade iônica são: $\mathrm{Sm}, \mathrm{Gd}$ e Y. A condutividade iônica dessas soluções sólidas a $800^{\circ} \mathrm{C}$ é equivalente àquela da zircônia estabilizada com ítria a $1000{ }^{\circ} \mathrm{C}$ [8]. Assim, essas soluções sólidas têm potencial aplicação em células a combustível de óxido sólido que operam a temperaturas intermediárias $\left(600-800{ }^{\circ} \mathrm{C}\right) \mathrm{e}$, como consequência vem sendo estudadas para fins de otimização de suas demais propriedades. Em geral, o uso de aditivos durante a sinterização de materiais cerâmicos constitui uma abordagem efetiva para a fabricação de produtos com alta densidade e tamanho controlado de grãos. Os aditivos utilizados na sinterização de materiais cerâmicos podem ter diversas finalidades: estabilizadores de fase, que têm por objetivo estabilizar à temperatura ambiente uma fase cristalina de alta temperatura; modificadores ou dopantes, que modificam 
uma ou mais propriedades, para que o material sinterizado apresente a propriedade requerida com magnitude otimizada e, os mais conhecidos, são os auxiliares de sinterização, que também podem ter diversas finalidades tais como, aumentar a taxa de densificação ou evitar o crescimento exagerado de grãos. Devido a esta multiplicidade de funções os efeitos produzidos pelos aditivos são ainda pouco conhecidos, e cada caso é estudado separadamente. Por isso, também, a seleção dos aditivos tem sido feita de forma empírica. Os principais resultados de trabalhos relacionados aos aditivos na céria estão centrados nos óxidos de terras raras e de terras alcalinas, por suas altas solubilidades. Deve-se, entretanto, separar o efeito principal do aditivo como modificador de propriedades, daquele empregado em pequenos teores, como aditivo secundário, cuja principal finalidade é de auxiliar a densificação ou retardar o crescimento de grãos, ou ainda, de formar uma fase secundária com características adequadas nos contornos de grão. Para a céria contendo terras raras, a condução iônica predomina sobre a eletrônica numa ampla faixa de temperatura e de pressão parcial de oxigênio. Entretanto, a condução eletrônica pode assumir valores consideráveis em altas temperaturas e baixas pressões de oxigênio quando o $\mathrm{Ce}^{4+}$ é reduzido a $\mathrm{Ce}^{3+} \mathrm{com}$ conseqüente redução na extensão do domínio eletrolítico. Assim, para a céria, as principais funções de um segundo aditivo são: contribuir para o aumento da extensão do domínio eletrolítico, auxiliar na "remoção" de impurezas existentes nos contornos de grão (efeito scavenger) ou ainda auxiliar na densificação.

Sabe-se que os óxidos de terras alcalinas são parcialmente solúveis na céria $[9,10]$. A diferença de valência entre os íons $\mathrm{Ce}^{4+}$ e $\mathrm{M}^{2+}(\mathrm{M}=$ cátion de terra alcalina) favorece a formação de vacâncias de oxigênio, responsáveis pelo processo de condução na céria. Assim, a adição de terras alcalinas à céria foi considerada por causa de seu potencial para aumentar a condutividade iônica.

O aumento na condutividade elétrica da céria com adição de $\mathrm{SrO}$ foi comprovado por diversos pesquisadores [1115]. Esse resultado foi interpretado como conseqüência da incorporação das terras alcalinas na estrutura cristalina da matriz, observada por medidas de XPS [11]. Entretanto, a adição de $\mathrm{SrO}$ à céria resultou em degradação da densidade [12] e o limite de solubilidade foi determinado como sendo apenas $4 \%$ mol a $1430{ }^{\circ} \mathrm{C}$. Foi mostrado que a adição de $\mathrm{SrO}$ à céria- $10 \%$ mol gadolínia beneficia a condutividade elétrica por meio do efeito scavenger [13, 14]. A análise por microssonda eletrônica foi utilizada para traçar um perfil de concentração para o $\mathrm{Sr}$ e outro para o $\mathrm{Si}$, este último proveniente de sílica, impureza comumente encontrada na céria. Como resultado mais significativo obtiveram aumento na condutividade com a incorporação de $\mathrm{SrO}$. O perfil de concentração resultante mostrou que nas regiões mais externas das amostras havia maior concentração de $\mathrm{Sr}$ e menor de Si. Foi mostrado que a forma como o aditivo é incorporado causa modificações diferentes tanto na microestrutura quanto na condutividade elétrica [15]. $\mathrm{A}$ introdução do $\mathrm{SrO}$ por método químico resultou em aumento da condutividade elétrica e da densificação. A adição de $\mathrm{TiO}_{2}$ à céria foi pouco estudada, provavelmente porque a substituição parcial de $\mathrm{Ce}^{4+}$ por $\mathrm{Ti}^{4+}$ não resulta em alteração na concentração de vacâncias de oxigênio e, por conseqüência, na condutividade elétrica. Jurado [16], entretanto, mostrou que este aditivo secundário dá origem a uma fase intergranular de baixa resistividade permitindo, dessa forma, reduzir o bloqueio aos portadores de carga nos contornos de grão. Foram reportadas melhorias na densificação da céria-samária que atingiu densidade próxima à teórica com adição de $\mathrm{TiO}_{2}$ [17]. Foi mostrado também que o aumento no teor de $\mathrm{TiO}_{2}$ até $5 \% \mathrm{~mol}$ propicia aumento na densificação e redução no tamanho médio de grãos da céria-gadolínia [18]. Foi também detectada a fase $\mathrm{Gd}_{2} \mathrm{Ti}_{2} \mathrm{O}_{7}$ com estrutura pirocloro. Este resultado evidenciou que o aditivo favorece a segregação do gadolínio, quando em teores elevados, ou seja, acima do limite de solubilidade, que é de aproximadamente $1,2 \% \mathrm{~mol}$.

Com relação ao $\mathrm{SrTiO}_{3}$, não foram encontrados trabalhos nos quais este composto tenha sido utilizado como aditivo secundário. $\mathrm{O}$ titanato de estrôncio tem sido empregado com sucesso como substrato em filmes finos à base de céria, devido à similaridade nos parâmetros de rede de ambos os compostos. Disto resultaram filmes epitaxiais com elevada condutividade elétrica $[19,20]$.

Neste trabalho foram empregados como aditivos secundários o $\mathrm{SrO}$, o $\mathrm{TiO}_{2}$ e o $\mathrm{SrTiO}_{3}$ visando conhecer um pouco mais dos efeitos desses cátions na microestrutura e na condutividade elétrica da céria- $20 \%$ mol gadolínia. O efeito destes aditivos em teores abaixo e acima do limite de solubilidade também foi investigado.

\section{EXPERIMENTAL}

Os materiais de partidas utilizados foram: $\mathrm{Ce}_{0,8} \mathrm{Gd}_{0,2} \mathrm{O}_{2-\delta}$ (> 99,5\%, Fuel Cell Materials), carbonato de estrôncio (99,99\%, Alfa Aesar) e óxido de titânio (99,95\%, Alfa Aesar). Esses materiais foram empregados como recebido, sem qualquer processamento prévio. O método utilizado para a preparação das diversas composições foi o da mistura dos reagentes de partida seguida de reação em estado sólido a alta temperatura.

Os aditivos foram introduzidos em teores de 1, 2,5 e 5\% mol em óxido. A Tabela I relaciona a denominação a ser utilizada para as diversas composições.

Inicialmente foi feita a secagem em estufa dos materiais de partida. Em seguida, quantidades estequiométricas foram

Tabela I - Denominação utilizada para as diferentes composições.

[Table I - Designation of the diverse compositions.]

\begin{tabular}{ll}
\hline Composição & Sigla \\
\hline céria-20\% mol gadolínia & CG \\
céria-20\% mol gadolínia contendo x $\mathrm{SrO}$ & $\mathrm{CGS}$ \\
céria-20\% mol gadolínia contendo $\mathrm{TiO}_{2}$ & $\mathrm{CGT}$ \\
céria-20\% mol gadolínia contendo x $\mathrm{SrTiO}_{3}$ & CGST \\
\hline
\end{tabular}


pesadas em balança analítica (Mettler, H315) e misturadas em almofariz de ágata em meio alcoólico. Após nova secagem as misturas foram compactadas em matriz de aço inoxidável a $400 \mathrm{kgf}$ formando discos de $10 \mathrm{~mm}$ de diâmetro e espessura de 2-3 $\mathrm{mm}$. Este procedimento foi realizado tanto para as composições contendo o carbonato de estrôncio quanto o óxido de titânio.

$\mathrm{O} \mathrm{SrTiO}_{3}$ foi preparado utilizando os reagentes de partida. $\mathrm{SrCO}_{3}$ e $\mathrm{TiO}_{2}$ foram secos, pesados em proporção estequiométrica e homogeneizados em recipiente de polietileno com meios de moagem de zircônia por $1 \mathrm{~h}$. A mistura foi calcinada a $1250{ }^{\circ} \mathrm{C}$ por $12 \mathrm{~h}$. A calcinação foi repetida mais uma vez para obtenção do titanato de estrôncio. Após a adição do $\mathrm{SrTiO}_{3}$ à solução sólida de céria-20\% mol gadolínia nas proporções desejadas, a mistura foi compactada de forma similar às demais composições.

A sinterização dos compactos foi feita ao ar em forno nas seguintes condições: a) para a céria-gadolínia contendo o carbonato de estrôncio as amostras foram aquecidas a $3{ }^{\circ} \mathrm{C} \cdot \mathrm{min}^{-1}$ até $1100{ }^{\circ} \mathrm{C}$ permanecendo nesta temperatura por $1 \mathrm{~h}$ para a decomposição térmica do carbonato de estrôncio. Em seguida foram aquecidas a $5{ }^{\circ} \mathrm{C} \cdot \mathrm{min}^{-1}$ até $1500{ }^{\circ} \mathrm{C}$ permanecendo $3 \mathrm{~h}$ neste patamar para a densificação; b) tanto a céria-gadolínia contendo o óxido de titânio quanto o titanato de estrôncio e a céria-gadolínia sem aditivos foram aquecidos a $3{ }^{\circ} \mathrm{C} \cdot \mathrm{min}^{-1}$ até $1100{ }^{\circ} \mathrm{C}$ e, em seguida, até $1500{ }^{\circ} \mathrm{C}$ (taxa de aquecimento de $5^{\circ} \mathrm{C} \cdot \mathrm{min}^{-1}$ ) na qual permaneceram por $3 \mathrm{~h}$. Neste caso, embora o aquecimento tenha sido similar ao das amostras contendo o carbonato de estrôncio, não foi realizado o patamar isotérmico a $1100{ }^{\circ} \mathrm{C}$.

Para as amostras contendo $1 \%$ mol de aditivo foi feito o estudo da retração linear em dilatômetro vertical (Anter 1161) com taxa de aquecimento $10^{\circ} \mathrm{C} \cdot \mathrm{min}^{-1}$ até $1500^{\circ} \mathrm{C}$.

A densidade aparente das diversas composições foi determinada pelo método da imersão. A porosidade aparente foi calculada a partir das medidas de densidade, de acordo com a norma ASTM C20-00. A verificação de fases foi feita por difração de raios X (Bruker-AXS, D8 Advance) na faixa angular $20^{\circ} \leqq 2 \Theta \leqq 80^{\circ}$, com passo $0,05^{\circ}$ e tempo $3 \mathrm{~s}$ com radiação Cuk $\alpha$ e filtro de Ni. A caracterização estrutural foi complementada por medidas de espectroscopia Raman (Renishaw, Invia Raman Microscope) utilizando a excitação de um laser de He-Ne com comprimento de onda $633 \mathrm{~nm}$ na faixa espectral $200-800 \mathrm{~cm}^{-1}$.

A observação da microestrutura foi feita em microscópio eletrônico de varredura (Philips, XL30) em amostras polidas e atacadas termicamente. A medida da condutividade elétrica foi feita por espectroscopia de impedância (HP 4192A), na faixa de freqüência de $5 \mathrm{~Hz}$ a $13 \mathrm{MHz}$, com eletrodos de prata.

\section{RESULTADOS E DISCUSSÃO}

A evolução da retração linear dos compactos contendo $1 \%$ mol de aditivos e da céria-gadolínia sem aditivos é mostrada na Fig. 1.

As curvas de retração linear evidenciam mudanças

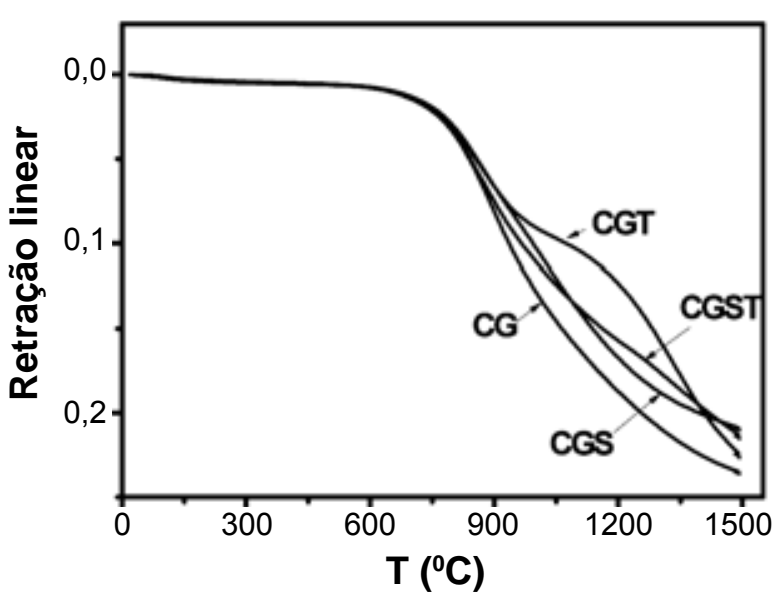

Figura 1: Curvas de retração linear dos compactos de cériagadolínia sem aditivos (CG) e contendo $1 \%$ mol de SrO (CGS), $\mathrm{TiO}_{2}$ (CGT) e $\mathrm{SrTiO}_{3}$ (CGST).

[Figure 1: Linear shrinkage curves of gadolinia-doped ceria without additives (CG) and with 1 mol\% of $\mathrm{SrO}(C G S)$, $\mathrm{TiO}_{2}(C G T)$ and $\mathrm{SrTiO}_{3}(\mathrm{CGST})$ compacts.]

significativas no processo de sinterização, mesmo para teor relativamente pequeno dos aditivos. A amostra sem aditivo secundário $(\mathrm{CG})$ é a que apresenta maior retração (aproximadamente 23\%) até $1500{ }^{\circ} \mathrm{C}$. Para a amostra contendo $\mathrm{TiO}_{2}$ (CGT) a taxa de retração diminui entre 900 e $1200{ }^{\circ} \mathrm{C}$, acelerando novamente em temperaturas mais altas e atingindo uma retração total de $22,5 \%$. Os compactos contendo $\mathrm{SrO}$ (CGS) e $\mathrm{SrTiO}_{3}$ (CGST) apresentam retração total de $21 \%$, aproximadamente. A temperatura inicial de retração não foi alterada pelos aditivos.

A Fig. 2 mostra a primeira derivada da retração linear para as diversas composições.

A curva derivada para a amostra CGT (Fig. 2a) exibe dois mínimos. Para a composição CGS (Fig. 2a) observase uma faixa de temperaturas na qual praticamente não ocorre retração, entre 800 e $1100^{\circ} \mathrm{C}$, provavelmente devido

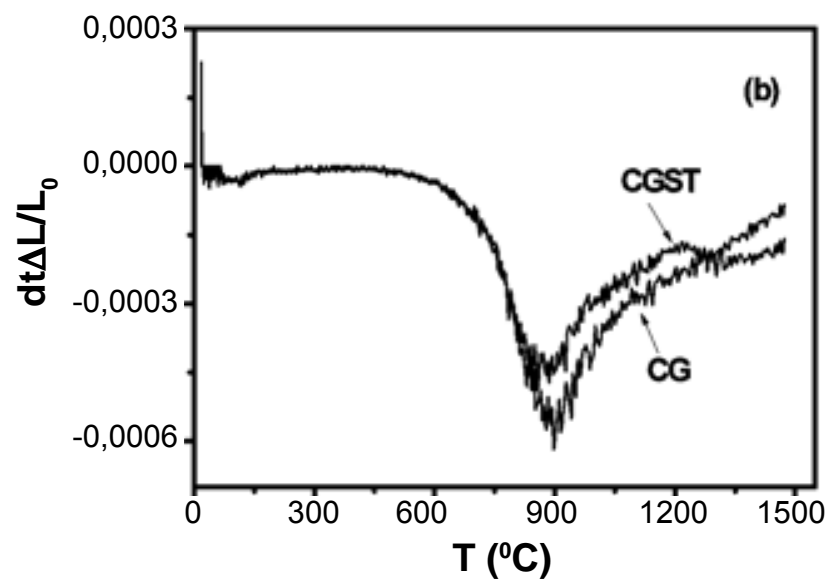

Figura 2: Curvas da primeira derivada da retração linear dos compactos: (a) CGS e CGT, e (b) CG e CGST.

[Figure 2: Curves of the linear shrinkage first derivative of compacts: (a) CGS and CGT, and (b) CG and CGST.] 
à decomposição térmica do carbonato de estrôncio. $\mathrm{O}$ carbonato de estrôncio decompõe-se termicamente em uma única etapa entre 800 e $1150{ }^{\circ} \mathrm{C}$. O compacto contendo $\mathrm{SrTiO}_{3}$ apresenta um mínimo acentuado (Fig. 2b) próximo ao da amostra sem segundo aditivo, CG (Fig. 2b).

Portanto, em tratamentos não isotérmicos pode-se afirmar que todos os aditivos retardam o processo de densificação, especialmente o SrO, como já observado [12]. $\mathrm{O}$ compacto contendo $\mathrm{TiO}_{2}$ é o que apresenta retração mais lenta a partir de $900{ }^{\circ} \mathrm{C}$, mas a densificação total é próxima à da céria-gadolínia sem aditivos. Os compactos contendo $\mathrm{SrO}$ e $\mathrm{SrTiO}_{3}$ apresentam retração total muito similar. Estes resultados evidenciam diferentes fenômenos que ocorrem durante o aquecimento dos compactos, o que não é possível avaliar nos tratamentos isotérmicos.

A Tabela II lista os valores de densidade relativa e porosidade aparente obtidos após sinterização a $1500{ }^{\circ} \mathrm{C}$ por $3 \mathrm{~h}$.

A amostra sem aditivo secundário atingiu $97,5 \%$ da densidade teórica nas condições empregadas. Adição de $\mathrm{SrO}$, em teores pequenos $(1 \% \mathrm{~mol})$ resultou em diminuição da densidade e aumento da porosidade. Para teores mais elevados verifica-se o efeito oposto. Contudo, mesmo para $5 \%$ mol do aditivo, a densidade final é inferior àquela da amostra CG.

Adições de $\mathrm{TiO}_{2}$ resultaram em aumento substancial da densidade aparente. O efeito densificante do óxido de titânio havia sido relatado [17]. Por outro lado, a adição de $\mathrm{SrTiO}_{3}$ não influenciou, de forma significativa, a densidade e a porosidade da céria-gadolínia. É importante lembrar que as densidades dos aditivos não foram consideradas nos cálculos.

Todas as composições preparadas foram analisadas por difração de raios $\mathrm{X}$ e os difratogramas são semelhantes àquele da céria- $20 \%$ mol gadolínia. A Fig. 3 mostra, como exemplo, os difratogramas de raios $\mathrm{X}$ das amostras contendo $\mathrm{TiO}_{2}$.

Tabela II - Valores de densidade relativa (\% da densidade teórica, DT) e porosidade aparente (\%) após sinterização a $1500{ }^{\circ} \mathrm{C}$ por $3 \mathrm{~h}$.

[Table II - Values of relative density (\% of theoretical density, DT) and apparent porosity (\%) after sintering at $1500{ }^{\circ} \mathrm{C}$ for $3 \mathrm{~h}$.

\begin{tabular}{ccc}
\hline Material & $\begin{array}{c}\text { Densidade relativa } \\
(\% \mathrm{DT})\end{array}$ & $\begin{array}{c}\text { Porosidade aparente } \\
(\%)\end{array}$ \\
\hline $\mathrm{CG}$ & 97,5 & 0,1 \\
$1 \% \mathrm{SrO}$ & 90,6 & 1,3 \\
$2,5 \% \mathrm{SrO}$ & 94,6 & 0,6 \\
$5 \% \mathrm{SrO}$ & 95,8 & 0,2 \\
$1 \% \mathrm{TiO}_{2}$ & 99,8 & $\sim 0$ \\
$2,5 \% \mathrm{TiO}_{2}$ & 98,7 & $\sim 0$ \\
$5 \% \mathrm{TiO}_{2}$ & $\sim 100$ & $\sim 0$ \\
$1 \% \mathrm{SrTiO}_{3}$ & 95,6 & 0,68 \\
$2,5 \% \mathrm{SrTiO}_{3}$ & 97 & 0,05 \\
$5 \% \mathrm{SrTiO}_{3}$ & 97 & 0,1 \\
\hline
\end{tabular}

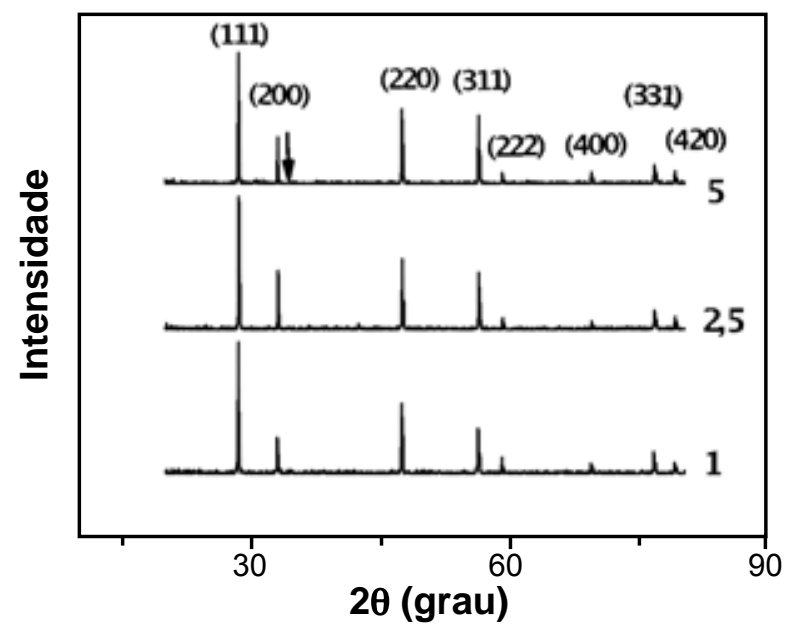

Figura 3: Difratogramas de raios $\mathrm{X}$ das amostras de cériagadolínia contendo diferentes teores de $\mathrm{TiO}_{2}$ após sinterização a $1500{ }^{\circ} \mathrm{C}$ por $3 \mathrm{~h}$.

[Figure 3: X-ray diffraction patterns of gadolinia-doped ceria containing different amounts of $\mathrm{TiO}_{2}$ after sintering at $1500{ }^{\circ} \mathrm{C}$ for 3 h.]

O perfil de difração foi indexado de acordo com aquele da céria-20\% mol gadolínia (ICSD 28-796). Não foram detectados picos de difração relacionados com outras fases, nem mesmo para a amostra com maior teor do aditivo, para a qual seria esperado detectar o pico de máxima intensidade (indicado por uma seta na Fig.) em $2 \theta=32,8^{\circ}$ do $\mathrm{Gd}_{2} \mathrm{Ti}_{2} \mathrm{O}_{7}$.

A caracterização estrutural foi também realizada por medidas de espectroscopia Raman. A Fig. 4 mostras os espectros obtidos para as amostras contendo (a) $\mathrm{SrO}$ e (b) $\mathrm{TiO}_{2}$.

Os espectros Raman de todas as composições investigadas são similares contendo uma banda predominante em aproximadamente $465 \mathrm{~cm}^{-1}$, que é o único modo permitido para a estrutura cúbica de faces centradas da céria. Além disso, na região de 550 a $650 \mathrm{~cm}^{-1}$ observam-se duas bandas de baixa intensidade. Essas bandas são atribuídas à formação de vacâncias pela introdução de cátions aliovalentes [21]. Nenhuma outra banda que pudesse ser atribuída a uma fase secundária foi detectada, exceto no espectro da amostra contendo $5 \% \mathrm{~mol} \mathrm{TiO}_{2}$ assinalado com * na Fig. 4 b.

A fase $\mathrm{Gd}_{2} \mathrm{Ti}_{2} \mathrm{O}_{7}$ possui estrutura pirocloro e apresenta 6 modos ativos Raman sendo o de maior intensidade localizado em $312 \mathrm{~cm}^{-1}$ [22]. Assim, este resultado confirma a formação da fase secundária de titanato de gadolínio, após remoção do gadolínio da solução sólida (exsolução).

A Fig. 5 mostra (a) uma micrografia representativa obtida em microscópio eletrônico de varredura e (b) um diagrama de impedância típico da céria- $20 \%$ mol gadolínia (CG) registrado a $309^{\circ} \mathrm{C}$.

A amostra é densa e os principais aspectos da microestrutura (Fig. 5a) revelam grãos com dimensões micrométrica e submicrométrica, e pouca porosidade. Os poros estão preferencialmente localizados nos contornos de grão e junções triplas. O diagrama de impedância (Fig. 5b) mostra três semicírculos na faixa de freqüência de $5 \mathrm{~Hz}$ a 13 

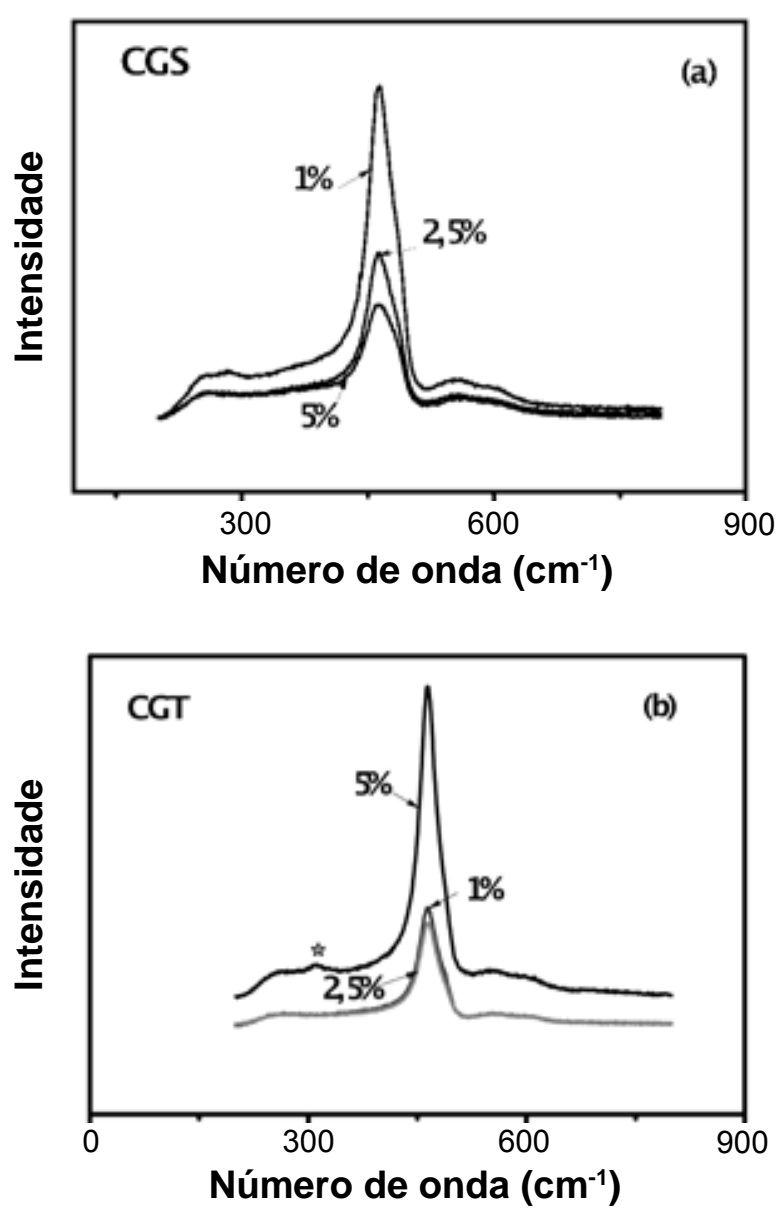

Figura 4: Espectros Raman das amostras sinterizadas a $1500{ }^{\circ} \mathrm{C}$ por $3 \mathrm{~h}$ contendo (a) $\mathrm{SrO}$ e (b) $\mathrm{TiO}_{2}$.

[Figure 4: Raman spectra of samples sintered at $1500{ }^{\circ} \mathrm{C}$ for $3 \mathrm{~h}$ containing (a) $\mathrm{SrO}$ and (b) $\mathrm{TiO}_{2}$.]

MHz. Nesta e nas demais figuras que mostram os diagramas de impedância, os números acima dos pontos experimentais representam o logaritmo decimal da freqüência. Observase que a amostra CG apresenta um efeito bloqueante dos contornos de grão comparativamente pequeno, tendo em conta os resultados já publicados $[9,12,13,15,16]$. Isto comprova a pureza elevada do material comercial.

A Fig. 6 mostra (a-c) as micrografias obtidas em microscópio eletrônico de varredura das composições contendo SrO, e (d) os diagramas de impedância correspondentes.

A composição contendo $1 \%$ mol $\mathrm{SrO}$ (Fig. 6a) exibe porosidade intragranular, e intergranular maior que na amostra sem aditivo secundário (Fig. 5a). A distribuição da porosidade é irregular e poucas regiões são densas. Por isso, a densificação desta composição é limitada ( 91\%). Os grãos têm tamanho pouco superior ao da amostra CG. Resultado similar foi obtido em amostras sintetizadas por método de solução [15]. A micrografia da amostra contendo $2,5 \% \mathrm{~mol}$ $\mathrm{SrO}$ (Fig. 6b) revela redução na porosidade e aumento no tamanho médio de grãos comparativamente à composição contendo $1 \%$ mol do aditivo. Alguns grãos apresentam tamanho de $\sim 5 \mu \mathrm{m}$ e a distribuição de tamanhos é alargada. $\mathrm{O}$ aumento do teor do aditivo para $5 \%$ mol (Fig. 6c) resulta em aumento adicional no tamanho médio de grãos tornando esta amostra bastante densa (Tabela II). Uma característica contrastante com as demais composições é que esta amostra exibe maior fração de arrancamentos localizados nas junções triplas. Isto pode ser atribuído ao acúmulo de sílica nas junções entre três grãos, resultante do efeito scavenger do $\mathrm{SrO}$, fragilizando essas regiões e, por essa razão, tornandoas mais susceptíveis para o arrancamento. Os grãos com maior tamanho apresentam superfícies curvas sugerindo a formação de pequena quantidade de líquido durante a sinterização.

Os diagramas de impedância das composições contendo $\mathrm{SrO}$ (Fig. 6d) evidenciam que o aditivo resultou em aumento na resistividade dos grãos. Este efeito pode ser uma consequência do aumento na fração de poros aprisionados no
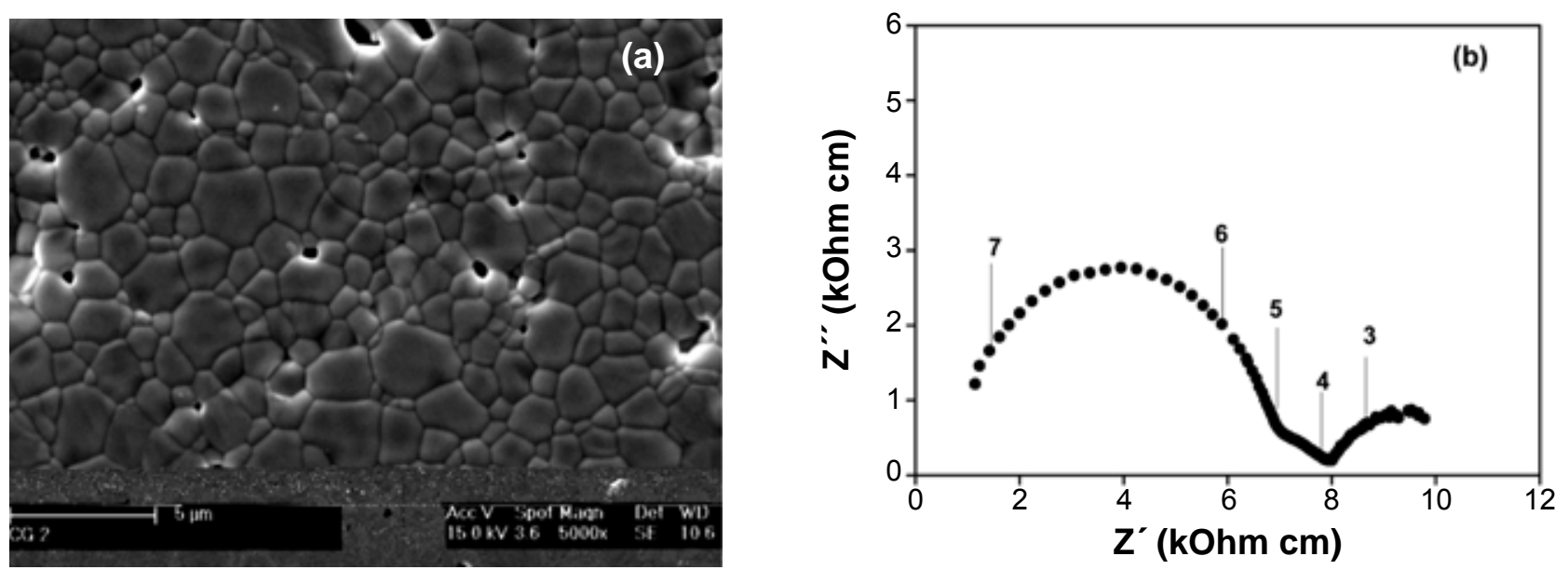

Figura 5: (a) Micrografia obtida em microscópio eletrônico de varredura, e (b) diagrama de impedância na temperatura de $309{ }^{\circ} \mathrm{C}$, da amostra CG sinterizada a $1500^{\circ} \mathrm{C}$ por $3 \mathrm{~h}$.

[Figure 5: (a) scanning electron microscopy micrograp and (b) impedance spectroscopy diagram at $309{ }^{\circ} \mathrm{C}$ of the sample CG sintered at $1500{ }^{\circ} \mathrm{C}$ for $\left.3 \mathrm{~h}.\right]$ 

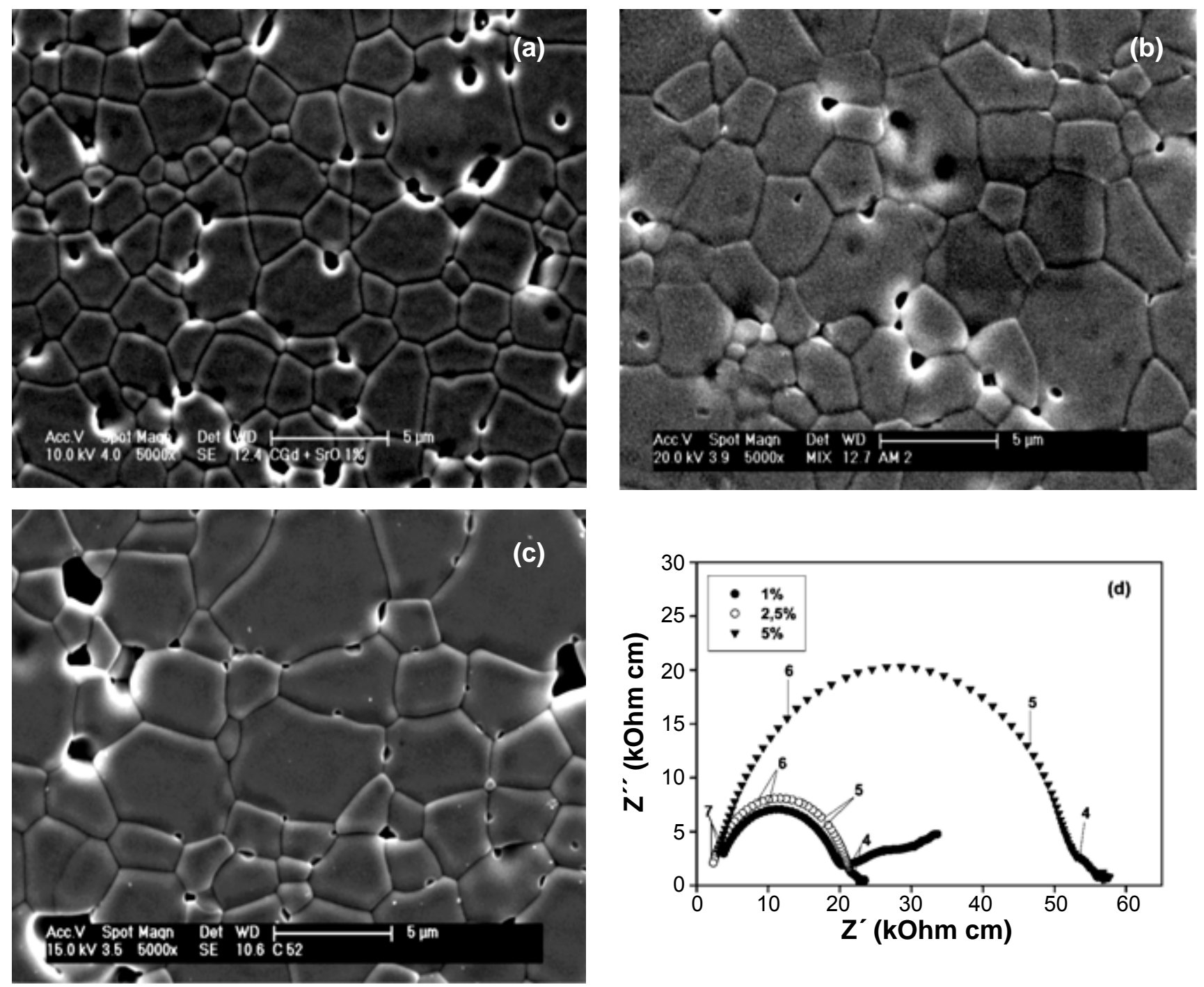

Figura 6: Micrografias obtidas em microscópio eletrônico de varredura de amostras contendo SrO sinterizadas a $1500{ }^{\circ} \mathrm{C}$ por 3 h: (a) 1 , (b) 2,5 e (c) $5 \%$ mol; e (d) diagramas de impedância registrados na temperatura de $308^{\circ} \mathrm{C}$.

[Figure 6: scanning electron microscopy micrographs of samples containing SrO sintered at $1500{ }^{\circ} \mathrm{C}$ for $3 \mathrm{~h}$ : (a) 1 , (b) 2.5 and (c) 5 mol\%; and (d) impedance spectroscopy diagrams recorded at $308^{\circ} \mathrm{C}$.]

interior dos grãos. $\mathrm{O}$ aumento na resistividade intragranular pode também ser resultante de uma diminuição na concentração de portadores de carga, ou de um aumento na barreira de potencial para a migração do portador de carga através da estrutura cristalina, ou ambos. As micrografias obtidas para estas amostras contendo $\mathrm{SrO}$ evidenciaram aumento da porosidade intragranular, mas não permitem saber se este é o único efeito responsável pelo aumento na resistividade intragranular. Por outro lado, o bloqueio aos portadores de carga nos contornos de grão tornou-se desprezível. Este resultado evidencia, pela primeira vez, o efeito do $\mathrm{SrO}$ nos contornos de grão, em amostras de cériagadolínia de alta pureza. Nos estudos anteriores $[13,14]$ o efeito scavenger foi demonstrado em amostras contendo sílica propositalmente adicionada.

A Fig. 7 mostra (a-c) micrografias das composições contendo $\mathrm{TiO}_{2}$ e (d) os diagramas de impedância correspondentes.
Todas as amostras contendo este aditivo apresentam porosidade reduzida e poucos arrancamentos. O tamanho médio de grãos aumenta consideravelmente com o aumento no teor do aditivo. Para a composição contendo $5 \%$ mol são observados grãos pequenos ao longo dos contornos de grão. Este grãos menores estão possivelmente relacionados com a fase pirocloro do $\mathrm{Gd}_{2} \mathrm{Ti}_{2} \mathrm{O}_{7}$ detectada por espectroscopia Raman (Fig. 4b). Esses grãos menores são também observados, em menor concentração, para a composição com $2,5 \% \mathrm{~mol}$. Assim, é possível que a fase pirocloro seja formada para teores menores do aditivo e não tenha sido detectada devido à limitação da técnica de medida. Os diagramas de impedância destas amostras (Fig. 7d) revelam comportamentos opostos de grãos e contornos de grão com $\mathrm{o}$ teor do aditivo.

Os resultados obtidos para adições de $\mathrm{SrTiO}_{3}$ são mostrados na Fig. 8.

Neste caso, para a composição contendo $1 \%$ mol do 

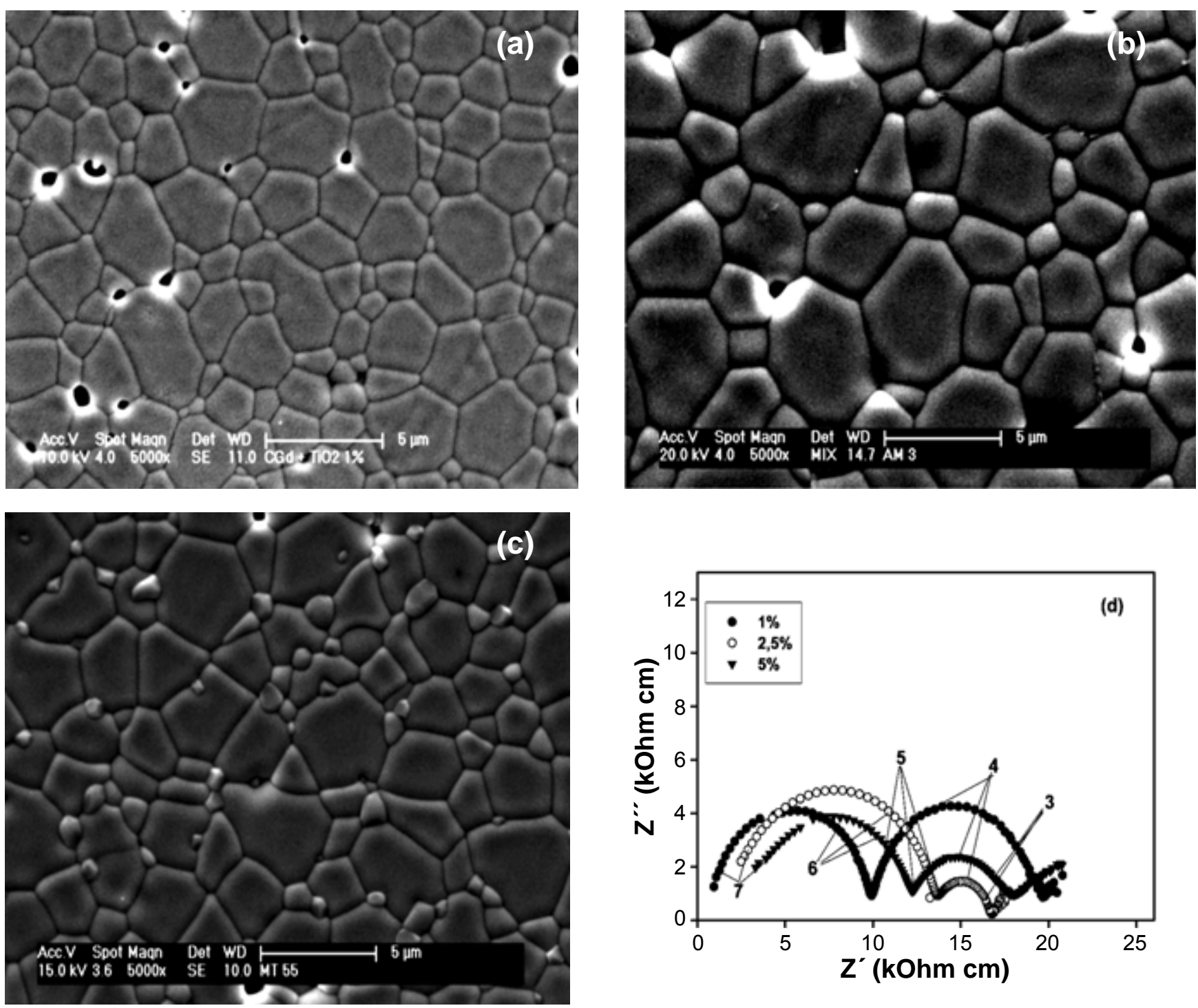

Figura 7: Micrografias obtidas em microscópio eletrônico de varredura de amostras contendo $\mathrm{TiO}_{2}$ sinterizadas a $1500{ }^{\circ} \mathrm{C}$ por 3 h: (a) 1 , (b) 2,5 e (c) $5 \%$ mol; e (d) diagramas de impedância registrados na temperatura de $260{ }^{\circ} \mathrm{C}$.

[Figure 7: scanning electron microscopy micrograph of samples containing TiO sintered at $1500{ }^{\circ} \mathrm{C}$ for $3 \mathrm{~h}$ : (a) 1 , (b) 2.5 and (c) 5 mol\%; and (d) impedance spectroscopy diagrams recorded at $260{ }^{\circ} \mathrm{C}$.]

aditivo (Fig. 8a) observam-se grãos com tamanho maior que o das demais amostras com igual teor de aditivo (Figs. 6a e 7a). O crescimento dos grãos foi acelerado tal que alguns contêm poros aprisionados, como aquele indicado por uma seta na Fig. 8a. A distribuição de tamanho dos grãos é alargada. Para teores mais elevados o crescimento de grãos é desacelerado. Para as composições contendo 2,5 e $5 \% \mathrm{~mol}$ do aditivo são observados grãos mais escuros e grãos de tamanho bastante reduzido, como indicado nas Figs. 8b e $8 \mathrm{c}$, respectivamente. Neste caso, é provável que estes grãos estejam relacionados com o titanato de estrôncio segregado nos contornos de grão e junções de vários grãos.

A Fig. 9 mostra os diagramas de impedância das amostras contendo $\mathrm{SrTiO}_{3}$. De forma análoga ao que ocorre com as amostras contendo titânia, também o efeito deste aditivo varia com o teor do mesmo.

Assim, pode-se dizer que o efeito dos aditivos $\mathrm{SrO}, \mathrm{TiO}_{2} \mathrm{e}$
$\mathrm{SrTiO}_{3}$ na microestrutura da céria-gadolínia depende do teor adicionado e da solubilidade. Somente para as composições contendo $1 \%$ mol o efeito dos aditivos é similar, pois todos favoreceram o crescimento de grãos da matriz de céria. $\mathrm{O}$ único aditivo que promoveu aumento no tamanho dos grãos para todas os teores empregados foi o $\mathrm{SrO}$. O TiO $\mathrm{Ti}_{2}$ removeu parte do gadolínio da solução sólida (exsolução do dopante) e deu origem a uma fase cristalina com estrutura do pirocloro $\left(\mathrm{Gd}_{2} \mathrm{Ti}_{2} \mathrm{O}_{7}\right)$ nos contornos de grão. $\mathrm{O} \mathrm{SrTiO}_{3}$ permaneceu segregado como fase secundária nos contornos de grão.

$\mathrm{O}$ efeito dos aditivos na condutividade elétrica da céria-20\% mol gadolínia podem ser melhor visualizados por meio dos gráficos de Arrhenius mostrados nas Figs. 10-13. Na Fig. 10 são mostrados os gráficos de Arrhenius da cériagadolínia sem aditivo secundário.

A dependência da condutividade dos grãos (g) e dos contornos de grão $(\mathrm{cg})$ pode ser representada por 

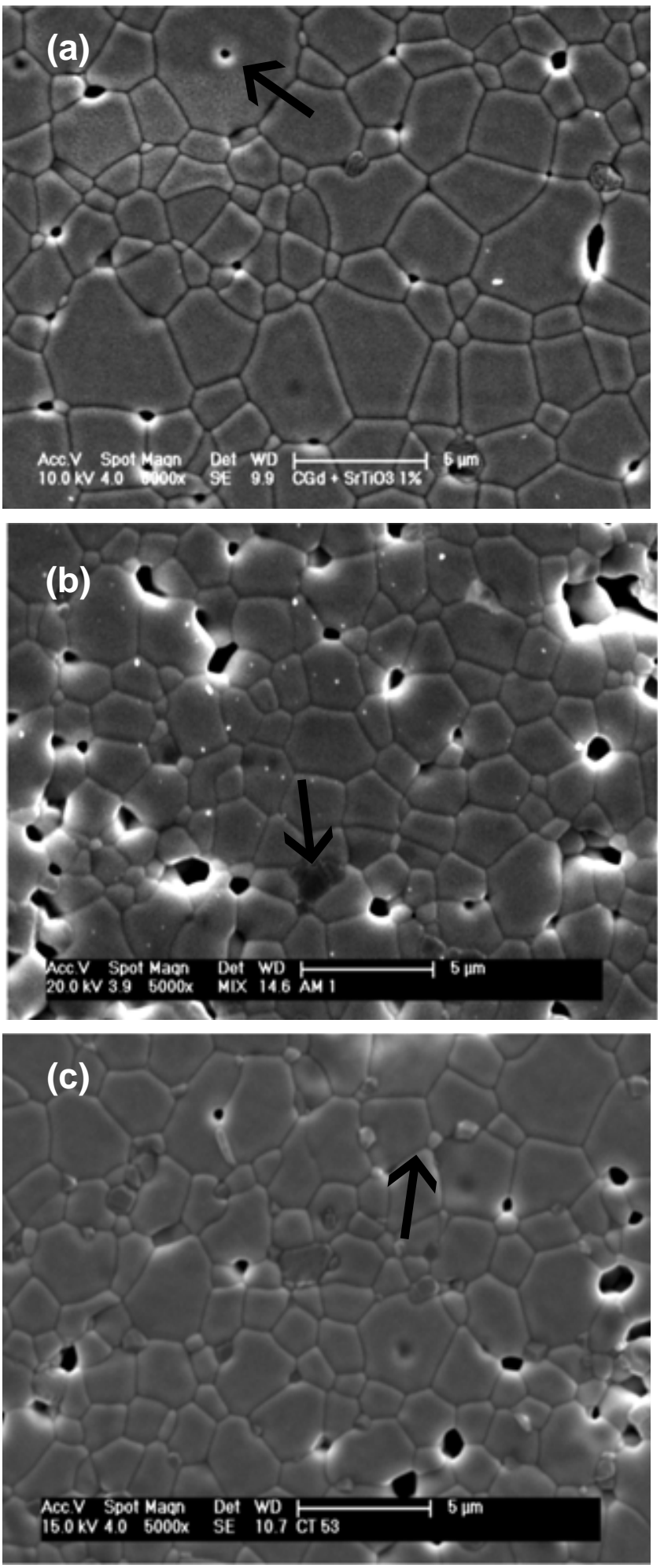

Figura 8: Micrografias obtidas em microscópio eletrônico de varredura de amostras contendo $\mathrm{SrTiO}_{3}$ sinterizadas a $1500{ }^{\circ} \mathrm{C}$ por $3 \mathrm{~h}$ : (a) 1 , (b) 2,5 e (c) $5 \%$ mol.

[Figure 8: scanning electron microscopy micrographs of samples containing $\mathrm{SrTiO}_{3}$ sintered at $1500{ }^{\circ} \mathrm{C}$ for $3 \mathrm{~h}$ : (a) 1 , (b) 2.5 and (c) $5 \mathrm{~mol} \%$.

um segmento de reta indicando um único mecanismo de condução, no intervalo de temperaturas em que as medidas foram realizadas. Os segmentos de reta são
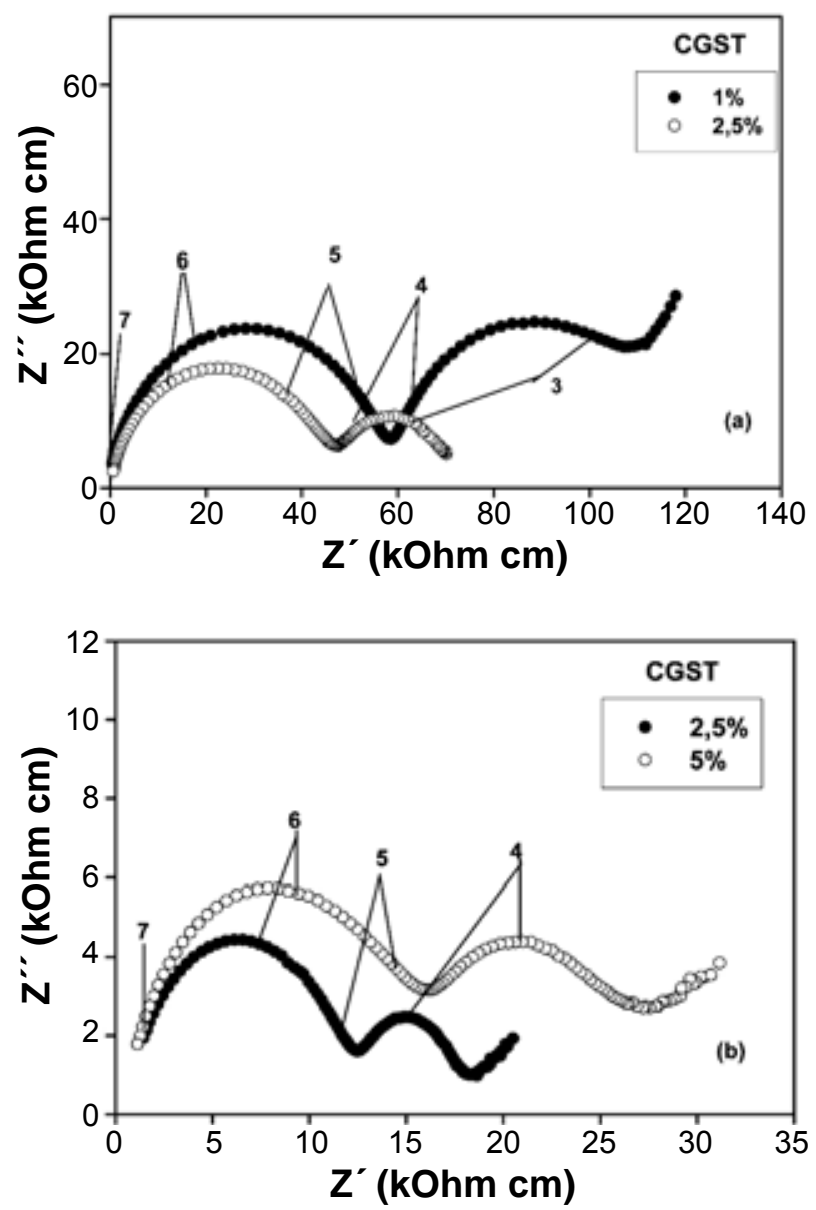

Figura 9: Diagramas de impedância de amostras contendo $\mathrm{SrTiO}_{3}$ sinterizadas a $1500{ }^{\circ} \mathrm{C}$ for $3 \mathrm{~h}$ (a) $258 \mathrm{e} \mathrm{(b)} 301^{\circ} \mathrm{C}$.

[Figure 9: Impedance spectroscopy diagrams of samples containing $\mathrm{SrTiO}_{3}$ sintered at $1500{ }^{\circ} \mathrm{C}$ for $3 \mathrm{~h}$ recorded at (a) 258 and (b) $\left.301{ }^{\circ} \mathrm{C}.\right]$

aproximadamente paralelos mostrando que as energias de ativação correspondentes têm valores muito próximos.

Os efeitos da adição de $\mathrm{SrO}$ na condutividade elétrica da matriz de céria (Fig. 11) foram avaliados somente para os grãos, uma vez que o bloqueio exercido pelos contornos de grão ao transporte de massa se tornou desprezível para este aditivo.

A condutividade intragranular (ou dos grãos) diminui gradativamente com o aumento no teor de $\mathrm{SrO}$. Este resultado mostra que este aditivo possui maior solubilidade que os demais, e que seu efeito é prejudicial à condutividade intragranular da céria-gadolínia. Essa redução na condutividade elétrica pode ser relacionada com a diminuição da densidade sinterizada. Apesar disto, o aditivo exerce efeito benéfico para a condutividade dos contornos de grão.

A dependência da condutividade elétrica com a temperatura para as amostras contendo $\mathrm{TiO}_{2}$ é mostrada na Fig. 12 para os grãos (a) e contornos de grão (b).

A condutividade intragranular (Fig. 12a) apresenta fraca dependência com o teor de $\mathrm{TiO}_{2}$, o que é uma consequência de sua baixa solubilidade $(\sim 1 \%)$ na matriz de céria. $O$ 


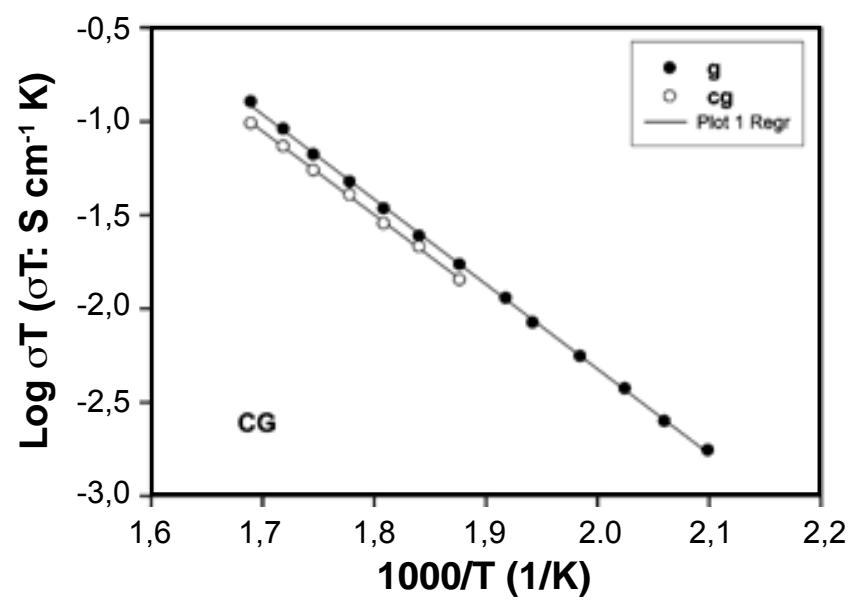

Figura 10: Gráficos de Arrhenius da condutividade elétrica da céria-gadolínia: g - grãos, cg - contornos de grão.

[Figure 10: Arrhenius plots of the electrical conductivity of gadolinia-doped ceria: $g$-grains, $c g$-grain boundaries.]

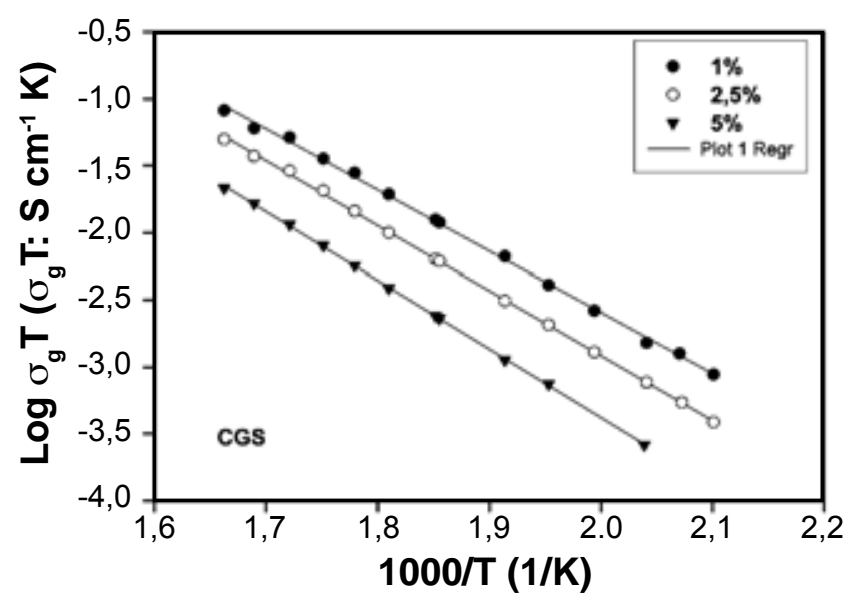

Figura 11: Gráficos de Arrhenius da condutividade elétrica intragranular da céria-gadolínia com adições de SrO.

[Figure 11: Arrhenius plots of the intragranular conductivity of gadolinia-doped ceria with $\mathrm{SrO}$ additions.]

bloqueio aos portadores de carga nos contornos de grão (Fig. $12 \mathrm{~b}$ ), entretanto, diminui com o aumento no teor do aditivo, e volta a aumentar para a composição contendo $5 \% \mathrm{~mol}$. Neste sistema alguns fenômenos ocorrem simultaneamente e outros sucessivamente: i) aumento no tamanho médio de grãos com consequente redução na área de contornos de grão, ii) segregação do aditivo (Ti), iii) exsolução do dopante $(\mathrm{Gd})$, e iv) formação da fase pirocloro $\mathrm{Gd}_{2} \mathrm{Ti}_{2} \mathrm{O}_{7}$. A redução na área total de contornos de grão e a formação da fase pirocloro devem resultar em aumento na condutividade elétrica dos contornos de grão, enquanto que a segregação do aditivo é esperada exercer o efeito oposto. A exsolução do dopante é prejudicial, pois modifica a química local. Assim, todos estes fenômenos contribuem de alguma forma, para o resultado obtido.

Os gráficos de Arrhenius das composições contendo $\mathrm{SrTiO}_{3}$ na Fig. 13 mostram que a condutividade
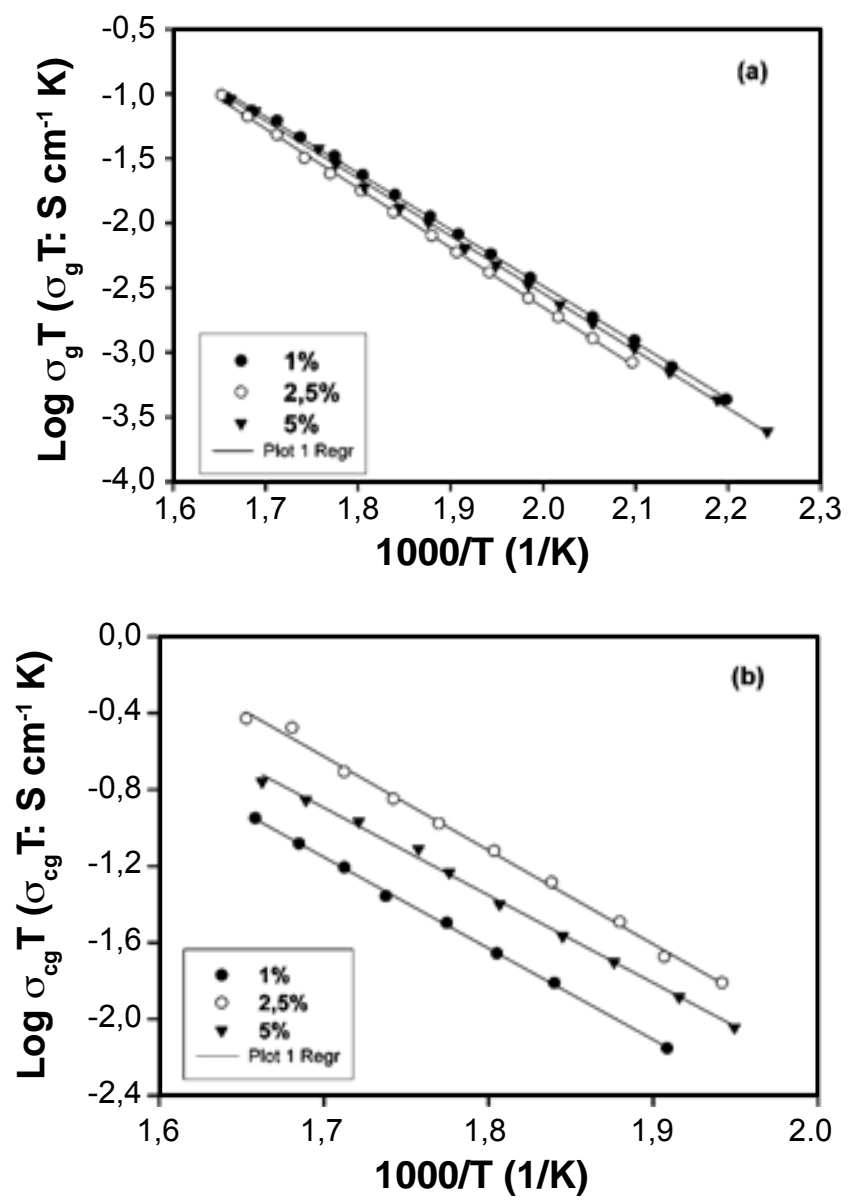

Figura 12: Gráficos de Arrhenius da condutividade elétrica da céria-gadolínia com adições de $\mathrm{TiO}_{2}$ : (a) grãos e (b) contornos de grão.

[Figure 12: Arrhenius plots of the electrical conductivity of gadolinia-doped ceria with $\mathrm{TiO}_{2}$ additions: (a) grain and (b) grain boundary.]

intragranular (a) também apresenta fraca dependência com o teor do aditivo demonstrando que este tem solubilidade desprezível na matriz, da mesma forma que o $\mathrm{TiO}_{2}$ (Fig. 12a). A condutividade intergranular (b), contudo, apresenta comportamento diferente daquele dos demais aditivos. $\mathrm{O}$ aumento de 1 para 2,5\% de $\mathrm{SrTiO}_{3}$ resultou em aumento da condutividade intergranular e uma mudança suave na inclinação da reta. Com aumento de 2,5 para 5\% mol do aditivo, a mudança de inclinação, para valores menores de energia de ativação, é mais drástica.

A Tabela III lista os valores de energia aparente de ativação do processo de condução através dos grãos e contornos de grão calculados a partir do coeficiente angular dos gráficos de Arrhenius.

De forma geral, os valores de energia de ativação estão de acordo com o esperado para condutores de íons oxigênio $(\sim 1 \mathrm{eV})$ [23]. Para as amostras com teores crescentes de SrO nota-se aumento no valor da energia de ativação intragranular, o que explica a correspondente diminuição da respectiva condutividade. Portanto, o $\mathrm{SrO}$, como aditivo secundário à céria-gadolínia, promove aumento da condução 

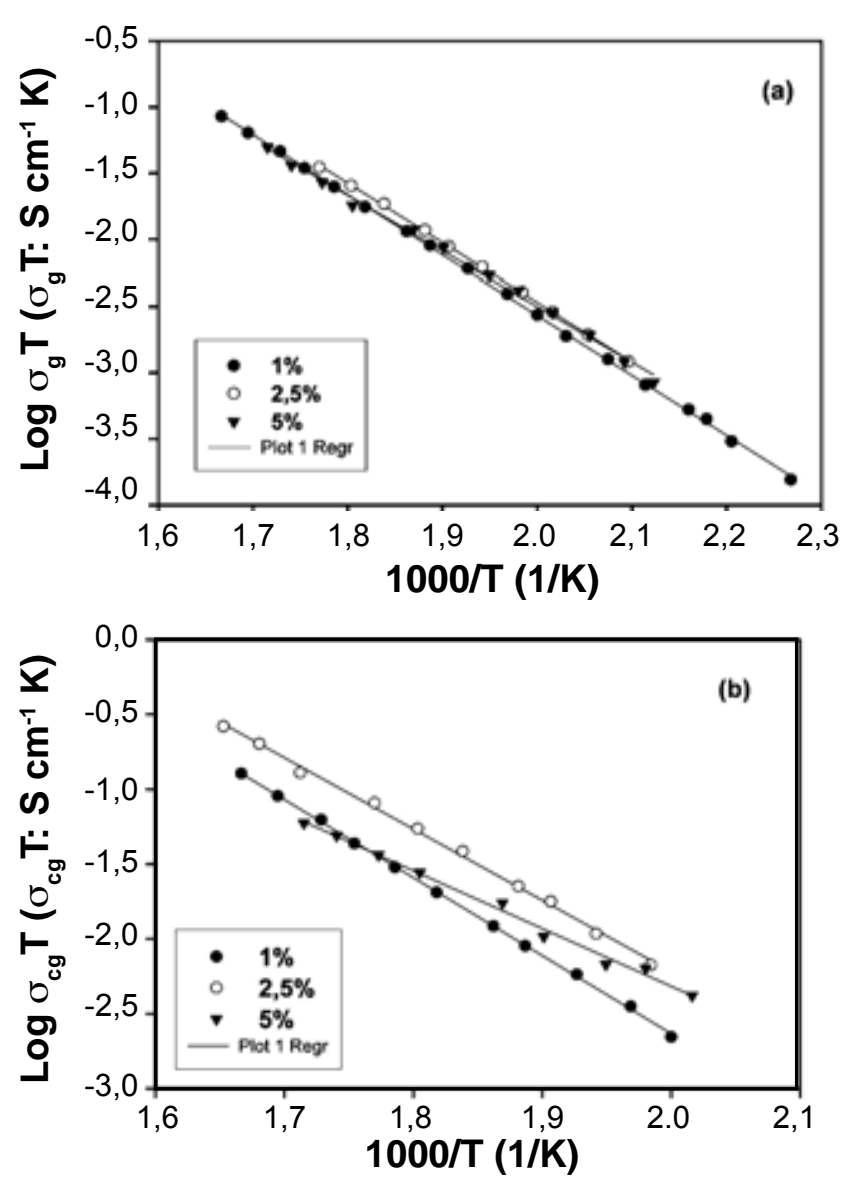

Figura 13: Gráficos de Arrhenius da condutividade elétrica da céria-gadolínia com adições de $\mathrm{SrTiO}_{3}$ : (a) grãos, e (b) contornos de grão.

[Figure 13: Arrhenius plots of the electrical conductivity of gadolinia-doped ceria with $\mathrm{SrTiO}_{3}$ additions: (a) grain and (b) grain boundary.]

Tabela III - Valores de energia aparente de ativação (E) do processo de condução intragranular (g) e intergranular (cg). [Table III - Values of the apparent activation energy (E) for grain (g) and grain boundary (cg) conductivities.]

\begin{tabular}{ccc}
\hline Composição & $\begin{array}{c}\mathbf{E}_{\mathbf{g}} \\
( \pm \mathbf{0 , 0 5} \mathbf{~ e V})\end{array}$ & $\begin{array}{c}\mathbf{E}_{\mathbf{c g}} \\
(\mathbf{0} \mathbf{0 , 0 5} \mathbf{~ e V})\end{array}$ \\
\hline $\mathrm{CG}$ & 0,89 & 0,88 \\
$1 \% \mathrm{SrO}$ & 0,90 & - \\
$2,5 \% \mathrm{SrO}$ & 0,96 & - \\
$5 \% \mathrm{SrO}$ & 1,02 & - \\
$1 \% \mathrm{TiO}_{2}$ & 0,88 & 0,95 \\
$2,5 \% \mathrm{TiO}_{2}$ & 0,91 & 0,97 \\
$5 \% \mathrm{TiO}_{2}$ & 0,88 & 0,91 \\
$1 \% \mathrm{SrTiO}_{3}$ & 0,90 & 1,03 \\
$2,5 \% \mathrm{SrTiO}_{3}$ & 0,89 & 0,95 \\
$5 \% \mathrm{SrTiO}_{3}$ & 0,83 & 0,77 \\
\hline
\end{tabular}

intergranular devido ao efeito scavenger e, diminuição da condutividade pelo aumento no valor da energia de ativação do processo.
Em princípio, a energia de ativação do processo de condução aumenta quando: i) diminui a concentração de portadores de carga disponíveis, ii) a mobilidade do portador de carga diminui devido a alterações produzidas na estrutura cristalina, ou iii) ambos os efeitos ocorrem simultaneamente. Como o $\mathrm{Sr}^{2+}$ possui valência inferior ao $\mathrm{Ce}^{4+}$ é esperado aumento na concentração de defeitos com sua introdução na estrutura cristalina da céria. Assim, é mais provável que a redução da mobilidade das vacâncias aniônicas seja responsável pelo aumento no valor da energia de ativação. Uma causa possível para a redução da mobilidade é a diferença dos raios catiônicos. $\mathrm{O} \mathrm{Sr}^{2+}$ possui um raio catiônico maior que o $\mathrm{Ce}^{4+} \mathrm{e}$ que o $\mathrm{Gd}^{3+}$ devendo dar origem a uma deformação da estrutura cristalina e consequente aumento na barreira de energia para a migração das vacâncias.

Para adições de $\mathrm{TiO}_{2}$ o valor da energia de ativação da condutividade intragranular é, dentro do erro experimental, essencialmente constante. Para o componente intergranular observa-se que aumentando o teor do aditivo houve pequeno aumento no valor da energia de ativação, mas com aumento subseqüente esta diminuiu. Neste caso dois fatores concorrem para estas mudanças: o acúmulo de $\mathrm{TiO}_{2}$ nos contornos de grão e a formação da fase secundária de titanato de gadolínio. O primeiro aumenta o valor da energia de ativação, pois representa um bloqueio adicional aos portadores de carga nos contornos de grão. O segundo diminui a energia de ativação, porque dá origem a uma fase cristalina com condutividade superior àquela do $\mathrm{TiO}_{2}$.

Para as composições contendo $\mathrm{SrTiO}_{3}$ o valor da energia de ativação intragranular apresenta pouca variação (dentro do erro experimental). O componente intergranular diminui sensivelmente com o aumento no teor do aditivo provavelmente devido à condução eletrônica do titanato de estrôncio.

\section{CONCLUSÕES}

Os aditivos estudados exercem efeitos distintos nas propriedades investigadas. $\mathrm{O} \mathrm{TiO}_{2}$ foi o aditivo que causou maior retração durante a sinterização da céria- $20 \% \mathrm{~mol}$ gadolínia. Nenhum dos aditivos alterou a temperatura inicial de retração. Na sinterização isotérmica os efeitos dos aditivos são também distintos. A céria-gadolínia sem aditivos secundários apresentou alta densidade relativa ( 97\%). Valores superiores foram obtidos com adições de $\mathrm{TiO}_{2}$, enquanto que o $\mathrm{SrO}$ prejudicou a densificação e o $\mathrm{SrTiO}_{3}$ não exerceu influência significativa nesta propriedade.

A fase pirocloro $\mathrm{Gd}_{2} \mathrm{Ti}_{2} \mathrm{O}_{7}$ foi detectada em amostras de céria-gadolínia contendo $5 \%$ mol de titânia evidenciando que o aditivo promove a exsolução do gadolínio da solução sólida.

O SrO produziu aumento na concentração de poros e arrancamentos. $\mathrm{O} \mathrm{TiO}_{2}$ foi responsável por aumento considerável no tamanho dos grãos.

O bloqueio aos portadores de carga nos contornos de grão 
se tornou desprezível com a adição de SrO. A condutividade elétrica intragranular aumentou substancialmente com este aditivo devido ao aumento no valor da energia de ativação para a condução. Tanto o $\mathrm{TiO}_{2}$ quanto o $\mathrm{SrTiO}_{3}$ não exerceram influência significativa na condutividade intragranular. Ambos os aditivos aumentam o bloqueio nos contornos de grão, pois formam fases secundárias com menor condutividade que a matriz.

\section{AGRADECIMENTOS}

Os autores agradecem a FAPESP, CNPq, CAPES e CNEN pelo apoio financeiro, ao Laboratório de Microscopia Eletrônica do IPEN, e ao Laboratório de Espectroscopia Molecular do Instituto de Química da USP/SP.

\section{REFERÊNCIAS}

[1] A. Trovarelli, Catal. Rev. Sci. Eng. 38 (1996) 439.

[2] X. J. Yu, P. B. Xie, Q. D. Su, Phys. Chem. Chem. Phys. 3 (2001) 5266.

[3] J. L. Macmanus-Driscoll, S. R. Foltyn, Q.-X. Jia, H. Wang, A. Senquis, I. Civale, B. Mairov, M. E. Hawley, M. P. Maley, D. E. Peterson, Nature Mater. 3 (2004) 439.

[4] B. C. H. Steele, Nature 414 (2001) 345.

[5] N. Guillou, I. C. Nistor, H. Fues, H. Hahn, Nanostruct. Mater. 8 (1997) 545.

[6] S. Tsunekawa, T. Fukuda, A. Kasuya, J. Appl. Phys. 87 (2000) 1318.

[7] M. Yamashita, K. Kaneyama, S. Yabe, S. Yoshida, Y. Fujishiro, Y. Kawai, T. Sato, J. Mater. Sci. 37 (2002) 683.

[8] H. Yahiro, K. Eguchi, H. Arai, Solid State Ionics 36 (1989) 71.

[9] H. Yahiro, K. Eguchi, H. Arai, Solid State Ionics 21
(1986) 37.

[10] R. N. Blumenthal, J. E. Garnier, J. Solid State Chem. 16 (1976) 21.

[11] Y. Z. Ren, K. Jiang, H. X. Wang, J. Meng, Q. Su, J. Rare Earths 21 (2003) 461.

[12] M. Mori, E. Suda, B. Pacaud, K. Murai, T. Moriga, J. Power Sources 157 (2006) 688.

[13] D. K. Kim, P.-S. Cho, J.-H. Lee, D.-Y. Kim, H.-M. Park, G. Auchterlonie, J. Drennan, Electrochem. Solid State Lett. 10 (2007) B91.

[14] P.-S. Cho, Y. H. Cho, S. Y. Park, S. B. Lee, D.-Y. Kim, H.-M. Park, G. Auchterlonie, J. Drennan, J. Electrochem. Soc. 156 (2009) B339.

[15] A. L. Horovistiz, E. N. S. Muccillo, Solid State Ionics 225 (2012) 428.

[16] J. R. Jurado, J. Mater. Sci. 36 (2001) 1133.

[17] R. A. Cutler, D. L. Meixner, B. T. Henderson, K. N. Huntchings, D. M. Taylor, M. A. Wilson, Solid State Ionics 176 (2005) 2589.

[18] E. Yu. Pikalova, V. I. Maragou, A. K. Demin, A. A. Murashkina, P. E. Tsiakaras, Solid State Ionics 179 (2008) 1557.

[19] S. Sanna, V. Espósito, D. Pergolesi, A. Orsini, A. Tebano, S. Licoccia, G. Balestrino, E. Traversa, Adv. Funct. Mater. 19 (2009) 1713.

[20] K. M. Kant, V. Espósito, N. Pryds, Appl. Phys. Lett. 97 (2010) 143110.

[21] J. R. McBride, K. C. Hass, B. D. Poindexter, W. H. Weber, J. Appl. Phys. 76 (1994) 2435.

[22] A. F. Fuentes, K. Boulahia, M. Maczka, J. Hanuza, U. Amador, Solid State Sci. 7 (2005) 343.

[23] E. C. Subbarao, Solid electrolytes and their applications, Plenum Press, New York, (1980).

(Rec. 22/04/2013, Ac. 26/05/2013) 